\title{
Seismic Response Analysis of an Isolated Structure with QZS under Near-Fault Vertical Earthquakes
}

\author{
Dewen Liu, ${ }^{1}$ Yang Liu $\mathbb{D},{ }^{2}$ Dongfa Sheng, ${ }^{1}$ and Wenyuan Liao ${ }^{1}$ \\ ${ }^{1}$ College of Civil Engineering, Southwest Forestry University, Kunming, China \\ ${ }^{2}$ College of Civil Engineering, Tongji University, Shanghai 200092, China \\ Correspondence should be addressed to Yang Liu; winner5299@163.com
}

Received 31 October 2017; Revised 27 January 2018; Accepted 12 February 2018; Published 15 March 2018

Academic Editor: Mahmoud Bayat

Copyright (c) 2018 Dewen Liu et al. This is an open access article distributed under the Creative Commons Attribution License, which permits unrestricted use, distribution, and reproduction in any medium, provided the original work is properly cited.

\begin{abstract}
Seismic isolation devices are usually designed to protect structures from the strong horizontal component of earthquake ground shaking. However, the effect of near-fault (NF) vertical ground motions on seismic responses of buildings has become an important consideration due to the observed building damage caused by vertical excitation. As the structure needs to maintain its load bearing capacity, using the horizontal isolation strategy in vertical seismic isolation will lead to the problem of larger static displacement. In particular, the bearings may generate large deformation responses of isolators for NF vertical ground motions. A seismic isolation system including quasi-zero stiffness (QZS) and vertical damper (VD) is used to control NF vertical earthquakes. The characteristics of vertical seismic isolated structures incorporating QZS and VD are presented. The formula for the maximum bearing capacity of QZS isolation considering the stiffness of vertical spring components is obtained by theoretical derivation. From the static analysis, it is found that the static capacity of the QZS isolation system with vertical seismic isolation components increases when the configurative parameter reduces. Seismic response analyses of the seismic isolated structure model with QZS and VD subjected to NF vertical earthquakes are conducted. The results show that seismic responses of the structure can be controlled by setting the appropriate static equilibrium position, vertical isolation period, and vertical damping ratio. Adding a damping ratio is effective in controlling the vertical large deformation of the isolator.
\end{abstract}

\section{Introduction}

Seismic isolation is one of most effective control ways to protect structural systems, nonstructural systems, and content from damage due to horizontal earthquake ground motions $[1,2]$. However, most buildings with seismic isolation devices are not designed to reduce the vertical component of earthquake ground motions [3]. In engineering design, the vertical-to-horizontal acceleration $(V / H)$ ratios of peak ground acceleration are usually recommended as $2 / 3$. In addition, the shape of the vertical response spectrum is similar to that of the horizontal response spectrum. In recent years, it was found that the areas near the epicenter and faults exert a strong vertical ground motion. The verticalto-horizontal $V / H$ response spectral ratios are greater than $2 / 3$. The ratios were smaller for long periods than for short periods. In the past researches, it has been found that the $V / H$ response spectral ratios are strongly dependent on period and site-to-source distance during the 1994 Northridge earthquake [4].

Vertical seismic isolation of a base-isolated structure has gained the interest of researchers. Various kinds of vertical seismic isolation devices have been developed to mitigate earthquakes, such as the low shape factor (LSF) elastomeric bearings [5], air springs consisting of cylinders filled with nitrogen gas [6,7], and vertical flexibility [8]. However, these approaches have their own drawbacks. The LSF approach is used only for low-rise structures. Vertical air springs and vertical flexibility are so costly and hence not likely to be widely applied. Furthermore, in order to achieve the seismic isolation effect, a longer vertical isolation period implies a lower vertical stiffness, which will lead to larger static displacement of the mass. This hinders the development of vertical seismic isolation systems. In recent years, negative stiffness structures (NSS) and quasi-zero stiffness (QZS) systems have been developed to overcome this disadvantage 


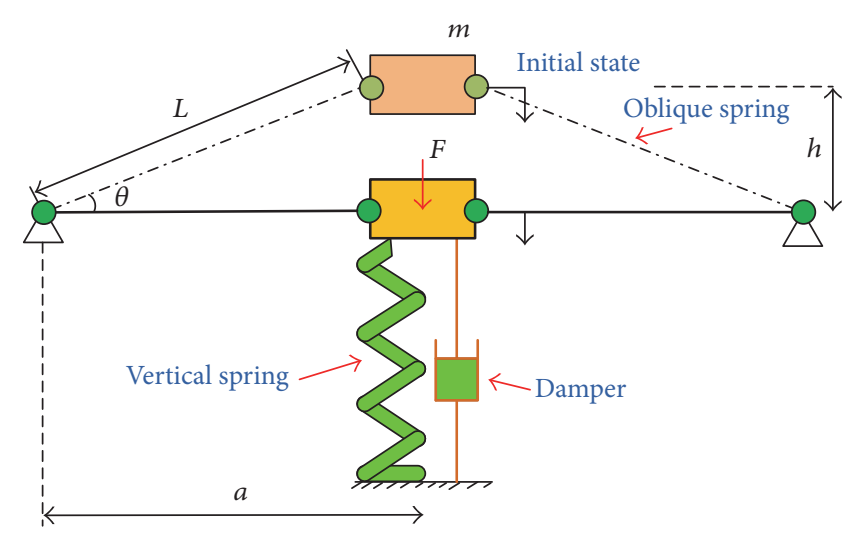

FIGURE 1: Model of seismic isolated structure with QZS.

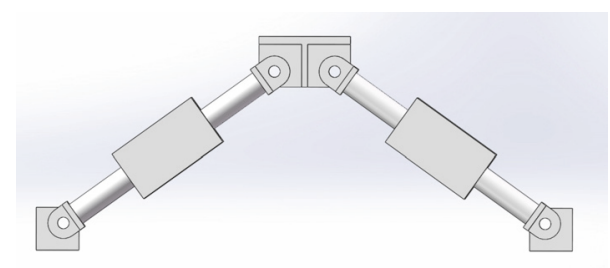

(a)

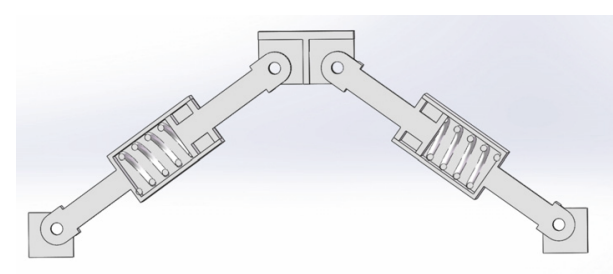

(b)

FIGURE 2: Model of oblique spring: (a) 3D, (b) cross section.

$[9,10]$. Nevertheless, the new approaches' applications are for the isolation of mechanical engineering only, and very limited researches focus on vertical seismic isolation.

Near-fault (NF) ground motions are characterized by long-period velocity and displacement pulses [11]. Past researches have revealed that seismic isolators can generate unacceptably large lateral displacement for NF motion due to resonance-like responses [12]. Accordingly, controlling the isolator's large displacement can be a challenging problem when developing a vertical isolation system [13]. By far, considering load bearing capacity and seismic response control for the structure under NF vertical ground motions has not been addressed. Therefore, focused on NF vertical seismic protection of structures such as span systems and base-isolated structures $[3,14]$, the objective of this study is to present a vertical isolation system that has sufficient static vertical rigidity to prevent large static deformations due to the self-weight of supported structures, while having enough dynamic flexibility and energy dissipation to reduce NF vertical seismic responses. Also, this approach is different from the horizontal isolation strategy.

In this paper, the characteristics of static load bearing capacity dynamic response of isolated structures with QZS under NF vertical ground motions are studied. The formula of maximum bearing capacity of quasi-zero stiffness isolation incorporating vertical seismic isolation components is theoretically derived. Subsequently, the effects of the static equilibrium position, vertical period, and damping ratio on the seismic responses for the isolated system with QZS are analyzed. Finally, comparison analyses of the QZS system and the seismic isolated system without QZS are presented to check the isolation effectiveness for the model against NF vertical ground motions.

\section{Seismic Isolated Structure Model with QZS}

Figure 1 shows the model of a seismic isolated structure with QZS. The system consists of a SDOF isolation system, supported on an intermediate mass $m$, together with a vertical stiffness $k_{v}$, in parallel with a viscous damper $c_{v}$ and two oblique springs with stiffness $k[15,16]$. Figure 2 shows the configuration of the oblique spring, which is composed of a sleeve, coil spring, and cylindrical bar. One end of the cylindrical bar is fixed to the spring, while the other end is connected to a cover plate by a hinge joint. The sleeve is connected to a base support by a hinge joint. The cylindrical bar can be directly inserted into the hole of the sleeve. Based on the configuration, the supported cover plate is allowed to move in the vertical plane. A force $F$ is applied at the mass center of the system. In the initial location, there is an angle between the oblique spring and the horizontal line. According to the static equilibrium condition, the static forcedeflection characteristic for seismic isolated structures with QZS is given by

$$
F=2 f \sin \theta+k_{v} u
$$

When it has a downward motion due to a vertical force $F$ applied to the mass of the seismic isolated structure, the vertical force can be described as

$$
F=2 k x \sin \theta+k_{v} u .
$$


According to the nonlinear geometric relationship, $\theta$ is taken as follows:

$$
\sin \theta=\frac{h-u}{\sqrt{a^{2}+(h-u)^{2}}} .
$$

If the oblique spring yields axial deflection, the relationship of $x$ and $u$ is calculated as

$$
x=\sqrt{a^{2}+h^{2}}-\sqrt{a^{2}+(h-u)^{2}}
$$

which can be written in a nondimensional form as

$$
\begin{aligned}
& \text { F } \\
& =2 k\left(\sqrt{a^{2}+h^{2}}-\sqrt{a^{2}+(h-u)^{2}}\right) \frac{h-u}{\sqrt{a^{2}+(h-u)^{2}}} \\
& +k_{v} u \\
& \widehat{F} \\
& =2\left(\sqrt{1-\gamma^{2}}-\widehat{u}\right)\left(\frac{1}{\sqrt{\gamma^{2}+\left(\sqrt{1-\gamma^{2}}-\widehat{u}\right)^{2}}}-1\right) \\
& +\mu \widehat{u}
\end{aligned}
$$

where $\widehat{u}=u / k L, \gamma=a / L, \mu=k_{v} / k$, and $\sqrt{a^{2}+h^{2}}=L$.

\section{Static Performance}

Initially, the mass is held in equilibrium by the compression force of the system, which is counterbalanced by the weight of the mass. Therefore, it is necessary to meet the load bearing capacity demand for seismic isolated structures with QZS. The static property should be considered in engineering design. Define $\sqrt{1-\gamma^{2}}-\widehat{u}=q$ as a new parameter; substituting it into (6) yields

$$
\widehat{F}=2 q\left[\left(\gamma^{2}+q^{2}\right)^{-1 / 2}-1\right]+\mu\left(\sqrt{1-\gamma^{2}}-q\right) .
$$

It is rational to obtain the maximum force of vertical capacity of a seismic isolated structure with QZS by differentiating (6) with respect to $q$. The formula is expressed as

$$
\begin{aligned}
\frac{\partial \widehat{F}}{\partial q} & =2\left[-q^{2}\left(\gamma^{2}+q^{2}\right)^{-3 / 2}+\left(\gamma^{2}+q^{2}\right)^{-1 / 2}-1\right]-\mu \\
& =0 .
\end{aligned}
$$

Setting $\left(\gamma^{2}+q^{2}\right)^{-1 / 2}=z$ and substituting it into (8), the following equation can be obtained:

$$
z=\left(\frac{2+\mu}{2 \gamma^{2}}\right)^{1 / 3}
$$

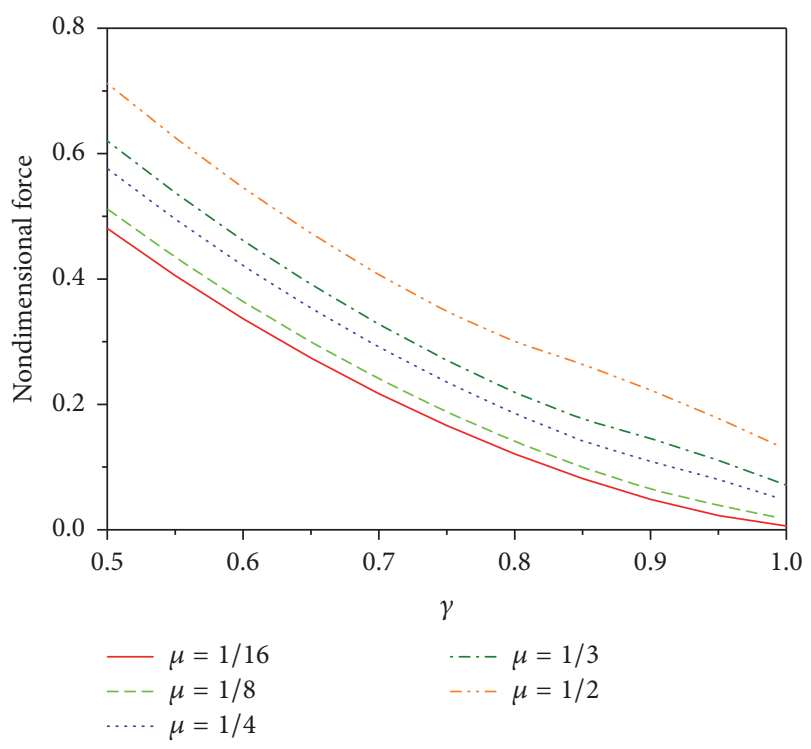

FIGURE 3: The nondimensional maximum force of vertical capacity of seismic isolated structures.

By substituting (9) into $\left(\gamma^{2}+q^{2}\right)^{-1 / 2}=z$, the nondimensional displacement is obtained as follows:

$$
q^{2}=\gamma^{2}\left[\left(\frac{2+\mu}{2}\right)^{-2 / 3} \gamma^{-2 / 3}-1\right] .
$$

By substituting (10) into (7), the maximum nondimensional force at the position $\sqrt{1-\gamma^{2}}-\widehat{u}=q$ is obtained as follows:

$$
\begin{array}{r}
\widehat{F}_{d}=2 \gamma \sqrt{\left(\frac{2+\mu}{2}\right)^{-2 / 3} \gamma^{-2 / 3}-1\left[\left(\frac{2+\mu}{2}\right)^{-2 / 3} \gamma^{-2 / 3}\right.} \\
-1]+\mu\left(\sqrt{1-\gamma^{2}}-\gamma \sqrt{\left(\frac{2+\mu}{2}\right)^{-2 / 3} \gamma^{-2 / 3}-1}\right) .
\end{array}
$$

The nondimensional maximum force of vertical capacity of a seismic isolated structure with QZS is plotted in Figure 3 for various values of $\gamma$ and $\mu$. It is found that the maximum force of vertical capacity of a seismic isolated structure with QZS is strongly dependent on $\gamma=a / L, \mu$, and $k_{v} L$.

With a mass loaded, when the system reaches the horizontal position $(u=h, y=0)$, the dynamic stiffness is zero. At the QZS state, the system is found to satisfy [15]

$$
\gamma=\frac{2 \beta}{2 \beta+1}
$$

where $\beta=k / k_{v}$.

In practice, engineers need to choose a convenient angle of the oblique spring to the horizon in degrees to design the seismic isolated structure with QZS. Normally, some special degrees such as $10^{\circ}, 30^{\circ}, 45^{\circ}$, and $60^{\circ}$ need be used to design the isolation bearing. When $\theta$ and $L$ are determined, $\gamma=a / L$ and QZS positioncan be preliminarily estimated. Parameters 
TABLE 1: Parameters for different angles.

\begin{tabular}{lccr}
\hline Degree & $\gamma=a / L$ & $\beta=k / k_{v}$ & $h$ \\
\hline 10 & 0.98 & 24.5 & $0.17 L$ \\
30 & 0.87 & 3.36 & $0.50 L$ \\
45 & 0.71 & 1.22 & $0.71 L$ \\
60 & 0.50 & 0.50 & $0.87 L$ \\
\hline
\end{tabular}

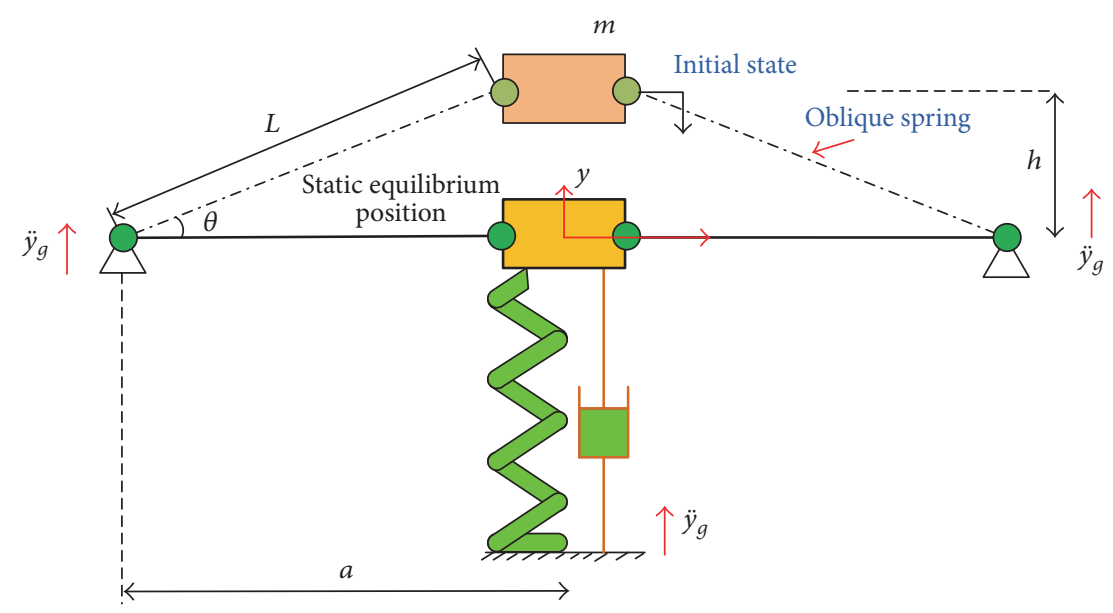

FIGURE 4: Seismic isolated structure model with QZS under vertical ground motion.

for different angles of the QZS isolator are presented in Table 1.

\section{Dynamic Equation of Motion for Seismic Input}

Figure 4 shows the state of the seismic isolated structure model under vertical ground motions $(y=h-u)$. When the mass oscillation reaches the steady state around the static equilibrium position, the dynamic equilibrium can be established as

$$
m \ddot{y}+2 k\left(1-\frac{L}{\sqrt{a^{2}+y^{2}}}\right) y+k_{v} y+c_{v} \dot{y}=-m \ddot{y}_{g}
$$

which can be written in a nondimensional form as

$$
\ddot{\hat{y}}+2 \omega^{2} \beta\left(1-\frac{1}{\sqrt{\gamma^{2}+\widehat{y}^{2}}}\right) \hat{y}+\omega^{2} \hat{y}+2 \omega \xi \dot{\hat{y}}=-\ddot{\hat{y_{g}}}
$$

where $\widehat{y}=y / L, \widehat{y_{g}}=y_{g} / L, \omega^{2}=k_{v} / m, \xi=c_{v} / 2 m \omega_{v}$, and $T=2 \pi \sqrt{m / k_{v}}$.

A time-stepping integration procedure has been applied to solve the equation of motion (13) numerically.

\section{Selection of Near-Fault Vertical Ground Motion Records}

Due to the uncertainty of earthquake events, selection of ground motion records has a significant impact on the variability of the structural response. Seismic codes for seismic design of buildings have prescribed general guidelines but they do not provide specifics for selecting the type of earthquake records for nonlinear dynamic analysis. Full agreement has not yet been reached regarding the establishment of commonly accepted selection criteria for earthquake records [17]. follows:

Selection criteria for earthquake records are given as

(i) These motions cover a moment magnitude range from 6.0 to 7.6 .

(ii) The rupture distance (closest distance from site to fault rupture plane) ranges from 0 to $10 \mathrm{~km}$.

(iii) Their shear-wave velocities at the uppermost $30 \mathrm{~m}$ $\left(v_{30}\right)$ soil profile are greater than $200 \mathrm{~m} / \mathrm{s}$.

20 different earthquake records (Table 2) are used to examine the effects of the characteristics of the excitation on the seismic response of the seismically isolated building with QZS. These earthquakes are obtained from the Pacific Earthquake Engineering Research Next Generation of Ground Motion Attenuation Models (PEER-NGA) ground motion database [18]. Elastic response spectra for $5 \%$ critical damping generated with thevertical components of the recorded 
TABLE 2: Near-fault pulse-like record data.

\begin{tabular}{|c|c|c|c|c|c|c|}
\hline Number & Event & Station & Moment magnitude & $R_{\text {rup }}(\mathrm{km})$ & Mechanism & $v_{30}$ \\
\hline$(1)$ & Loma Prieta, USA, 1989 & Saratoga-Aloha Ave., CMP & 6.9 & 8.50 & Reverse & 380.89 \\
\hline$(2)$ & Kocaeli, Turkey, 1999 & Izmit, IZT & 7.4 & 7.21 & Strike slip & 811.00 \\
\hline (3) & Chi-Chi, Taiwan, 1999 & TCU089 & 7.6 & 8.88 & Reverse & 671.52 \\
\hline$(4)$ & Chi-Chi, Taiwan, 1999 & CHY080 & 7.6 & 2.69 & Reverse & 496.21 \\
\hline$(5)$ & Chi-Chi, Taiwan, 1999 & TCU049 & 7.6 & 3.76 & Reverse & 487.27 \\
\hline$(6)$ & Chi-Chi, Taiwan, 1999 & TCU051 & 7.6 & 7.64 & Reverse & 350.06 \\
\hline$(7)$ & Chi-Chi, Taiwan, 1999 & TCU052 & 7.6 & 0.66 & Reverse & 579.1 \\
\hline$(8)$ & Chi-Chi, Taiwan, 1999 & TCU068 & 7.6 & 0.32 & Reverse & 487.34 \\
\hline$(9)$ & Chi-Chi, Taiwan, 1999 & TCU075 & 7.6 & 0.89 & Reverse & 573.02 \\
\hline$(10)$ & Chi-Chi, Taiwan, 1999 & TCU076 & 7.6 & 2.74 & Reverse & 614.98 \\
\hline$(11)$ & Imperial Valley, 1979 & El Centro \#4 & 6.53 & 7.05 & Strike slip & 208.91 \\
\hline$(12)$ & Imperial Valley, 1979 & El Centro \#5 & 6.53 & 3.95 & Strike slip & 205.63 \\
\hline$(13)$ & Imperial Valley, 1979 & El Centro \#7 & 6.53 & 0.56 & Strike slip & 201.51 \\
\hline$(14)$ & Imperial Valley, 1979 & El Centro \#10 & 6.53 & 8.6 & Strike slip & 202.85 \\
\hline$(15)$ & Imperial Valley, 1979 & El Centro Differential Array & 6.53 & 5.09 & Strike slip & 202.26 \\
\hline$(16)$ & Loma Prieta, USA, 1989 & Los Gatos-Lexington Dam & 6.9 & 5.02 & Reverse & 1070.32 \\
\hline$(17)$ & Tabas, Iran, 1978 & Tabas & 7.35 & 2.05 & Reverse & 767.77 \\
\hline$(18)$ & Northridge, USA, 1994 & LA Dam & 6.7 & 5.92 & Reverse & 628.99 \\
\hline (19) & Northridge, USA, 1994 & Pacoima Dam (upper left) & 6.7 & 7.01 & Reverse & 2016.33 \\
\hline$(20)$ & Kobe, Japan, 1995 & KJMA & 6.9 & 0.96 & Strike slip & 312 \\
\hline
\end{tabular}

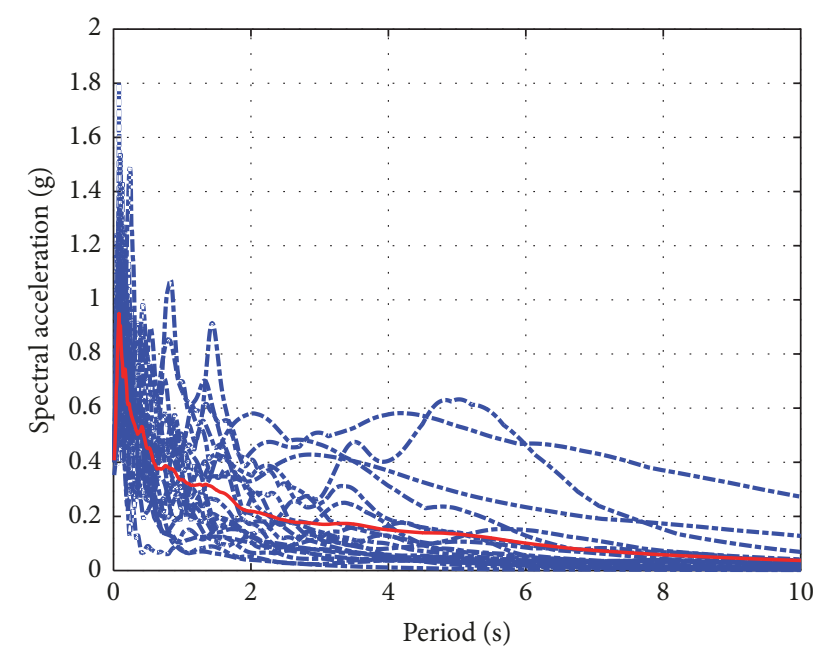

- Average

--- Individual

FIGURE 5: Elastic earthquake acceleration response spectra for 5\% critical damping.

ground motions are presented in Figure 5. Also plotted in this figure is the average spectrum. The peak acceleration (PGA) corresponding to earthquakes of major levels is specified to be $0.4 \mathrm{~g}$.

\section{Seismic Response Analysis}

In the previous researches, the horizontal position was a static equilibrium position. But in actual design, because of the

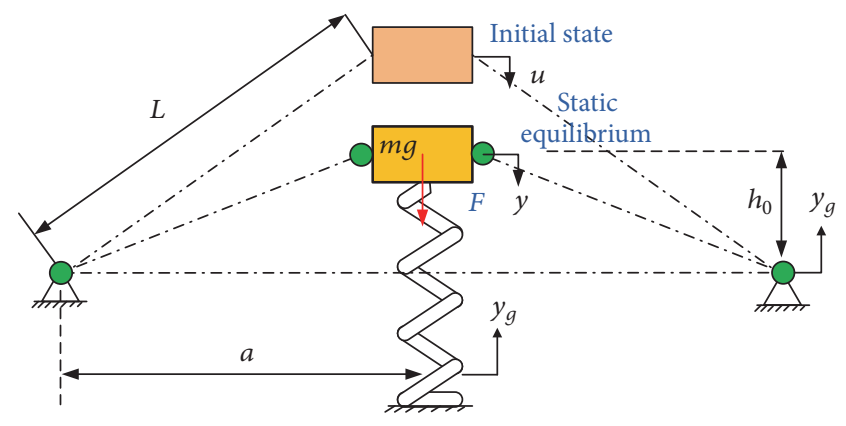

FIGURE 6: The dynamic analysis model of a QZS isolator at a static equilibrium position.

limited deformation ability and the uncertainty static estimation, the position of quasi-zero stiffness and static equilibrium is not always the same. It is essential to study the effect of static equilibrium on the seismic isolation performance of the system. The seismic responses of a base-isolated structure with different static equilibrium positions are investigated. Numerical studies are carried out using a mathematical model of the base-isolated structure to calculate the response of interest such as the peak absolute acceleration and the peak relative displacement of the isolation structure. A simplified 1DOF model of base isolation is shown in Figure 6. In Figure 6, the static equilibrium equation is

$$
2 k\left(L-\sqrt{a^{2}+h_{0}^{2}}\right) \frac{h_{0}}{\sqrt{a^{2}+h_{0}^{2}}}=m g
$$


The dynamic equilibrium equation is

$$
\begin{aligned}
m \ddot{y}+ & 2 k\left(L-\sqrt{a^{2}+\left(h_{0}-y\right)^{2}}\right) \frac{h_{0}-y}{\sqrt{a^{2}+\left(h_{0}-y\right)^{2}}} \\
& +k_{v} y+c \dot{y}=-m \ddot{y}_{g}+m g .
\end{aligned}
$$

Substituting (15) into (16) yields

$$
\begin{aligned}
m \ddot{y}+ & 2 k\left(L-\sqrt{a^{2}+\left(h_{0}-y\right)^{2}}\right) \frac{h_{0}-y}{\sqrt{a^{2}+\left(h_{0}-y\right)^{2}}} \\
& -2 k\left(L-\sqrt{a^{2}+h_{0}^{2}}\right) \frac{h_{0}}{\sqrt{a^{2}+h_{0}^{2}}}+k_{v} y+c_{v} \dot{y} \\
= & -m \ddot{y}_{g},
\end{aligned}
$$

which can be written as

$$
\begin{aligned}
\ddot{y}+ & 2 \omega^{2} \beta\left(L-\sqrt{a^{2}+\left(h_{0}-y\right)^{2}}\right) \frac{h_{0}-y}{\sqrt{a^{2}+\left(h_{0}-y\right)^{2}}} \\
& -2 \omega^{2} \beta\left(L-\sqrt{a^{2}+h_{0}^{2}}\right) \frac{h_{0}}{\sqrt{a^{2}+h_{0}^{2}}}+\omega^{2} y \\
& +2 \omega \xi \dot{y}=-\ddot{y}_{g},
\end{aligned}
$$

where $h_{0}$ is the height of the static equilibrium position.

The numerical procedure has been programmed by MATLAB software. To evaluate the performance of the system, the acceleration amplification coefficient (AAC) is an index to represent the isolation effect as follows:

$$
\eta=\frac{\max \left(\left|\ddot{\hat{y_{a}}}\right|\right)}{\widehat{A}}
$$

where $\ddot{\hat{y_{a}}}$ is the nondimensional acceleration of the system and $\widehat{A}$ is the maximum nondimensional seismic input acceleration.

Seismic responses of seismic isolated structures with QZS under vertical near-fault earthquakes are conducted to analyze the isolation effects. The comprehensive influences of static equilibrium position, vertical period, and damping ratio are investigated numerically. The length of oblique spring is $L=1 \mathrm{~m}$. The angle of the oblique spring to the horizon in degrees is $\theta=30^{\circ}$. We choose $\theta=30^{\circ}$ so that the vertical spring is not too lengthy. The initial height of the mass is $h=0.5 \mathrm{~m}$. The resulting value of $\gamma$ is 0.87 . It is assumed that the mass reaches the position at $y=h_{0}\left(\theta=0^{\circ}\right)$ which is a QZS position. In the case of QZS position, $\beta=3.36$. The elastic displacement versus force response curves of the system for different $h_{0}$ are shown in Figure 7 . It can be seen that when the height of the static equilibrium position increases, the QZS position coordinate also increases. In general, the QZS position coordinate is approximately equal to the static equilibrium position. However, the stiffness is always positive when $h_{0}=0.20 \mathrm{~m}$. In addition, with the height of the static equilibrium position increasing, the deformation of the isolator decreases. This indicates that a larger deformation space is needed in the design. The characteristics of the displacement versus force response curves for four near-fault ground motions have similar tendency. The characteristic of the isolator changes from pure-softening characteristic to pure-hardening characteristic.

The effect of the static equilibrium position and vertical period on the nondimensional displacement and AACs of the system is shown in Figure 8. It can be seen that the nondimensional displacement of the system decreases when the height of the static equilibrium position increases. The AAC decreases as the height of the static equilibrium position decreases and vertical period increases for the general trend. When vertical periods are relatively large, the AAC is less than 1.0 in the static equilibrium position range $\left(h_{0}=0-0.4 \mathrm{~m}\right)$, where the isolator is able to mitigate vibrations efficiently.

Figure 9 shows the nondimensional displacement and AAC of the system with a fixed vertical period for different static equilibrium positions and damping ratios. It shows that vertical seismic responses reduce when the damping ratio decreases. Compared with the case of $\xi=0.05$, the AAC is less than 1.0 for other cases. Although the increasing height of the static equilibrium position will result in a detrimental effect on seismic isolation, it is preferable to have relatively high damping to control the response of the system. It is worth noting that the isolation effect is not evident when the damping ratio changes from $\xi=0.15$ to $\xi=0.20$. This means that it is essential to choose befitting damper parameters for a good isolator.

Figure 10 shows the nondimensional displacement and AAC of the system with a fixed static equilibrium position for different vertical periods and damping ratios. It can be observed that the displacement of the system increases when vertical periods increase. A significant decrease in AAC of the system with the increase in vertical periods is observed in Figure 10(b).

\section{Parameter Design and Performance Evaluation}

According to previous static and seismic response results, QZS system parameters design and seismic performance evaluation are conducted. The design chart of the QZS system is shown in Figure 11. Assuming $T=2 \mathrm{~s}$ and rated load $F_{N}=$ $2000 \mathrm{kN}$, the vertical spring stiffness can be calculated using given parameters $\left(k_{v}=4 \pi^{2} F_{N} / T^{2} g=1971920 \mathrm{~N} / \mathrm{m}\right)$. The initial design length of the oblique spring is equal to $1 \mathrm{~m}$, and the initial design angle of the oblique spring to the horizon 


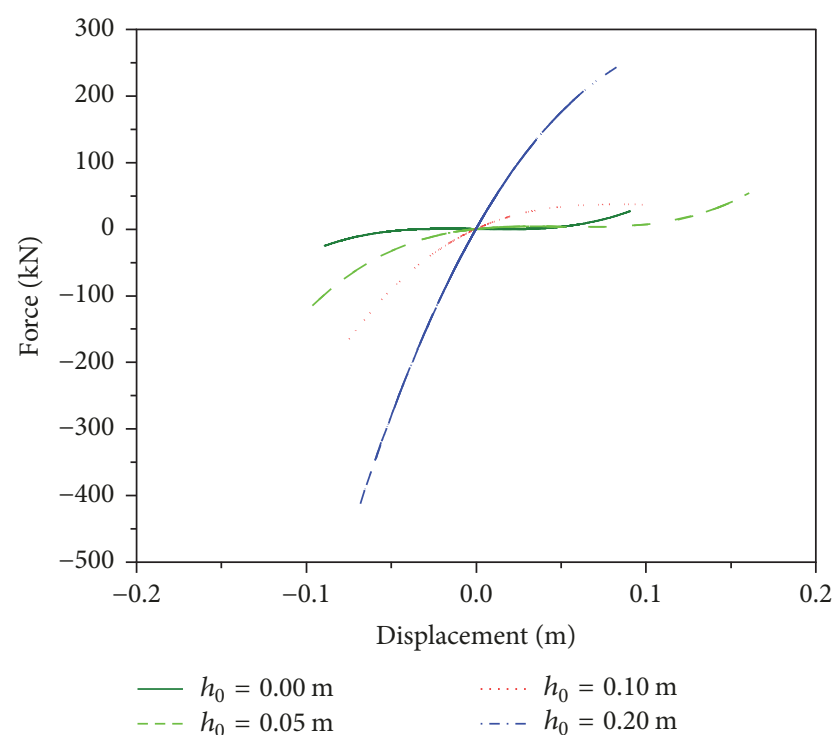

(a)

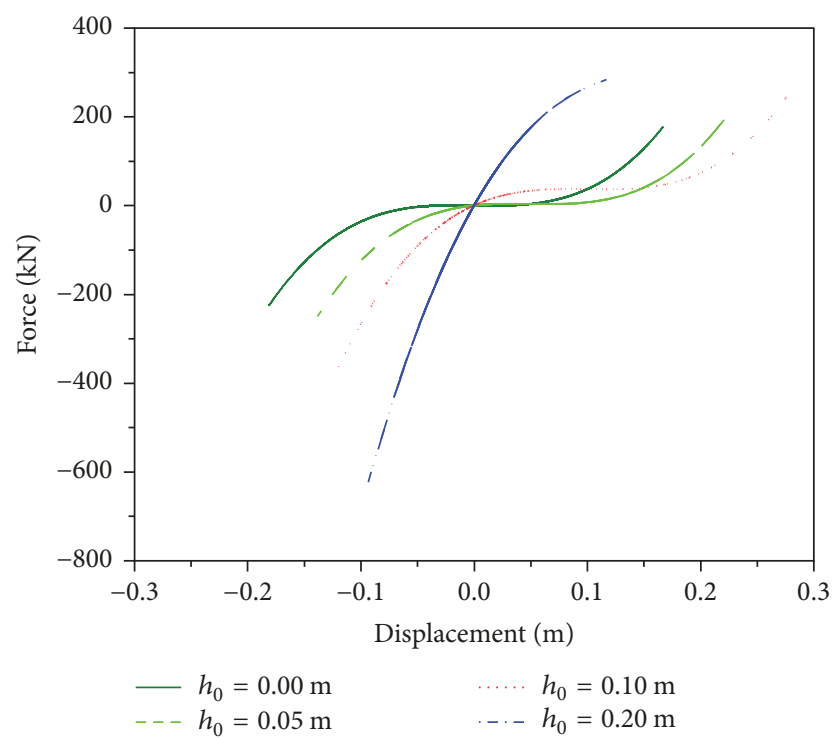

(c)

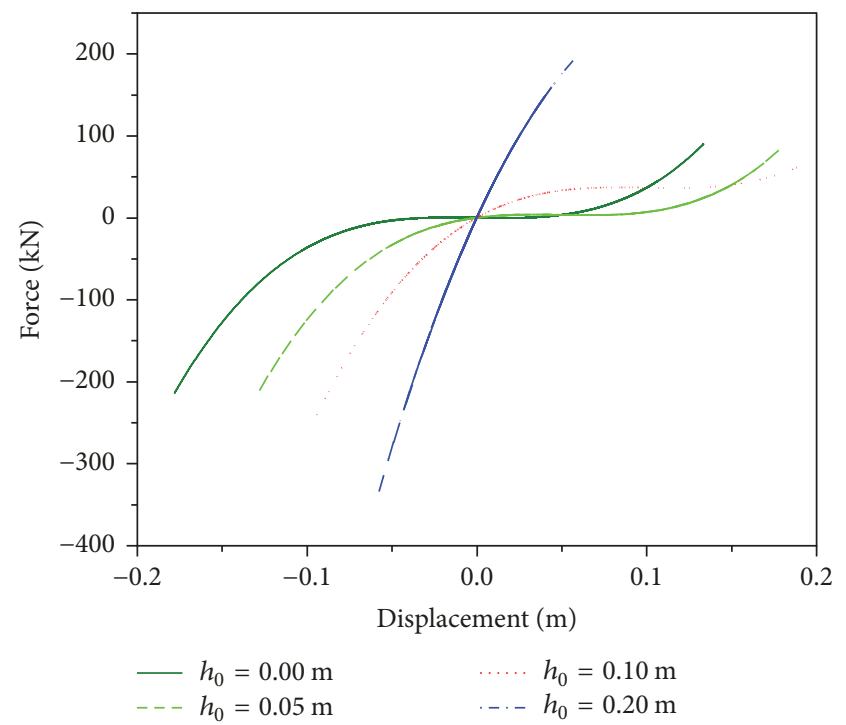

(b)

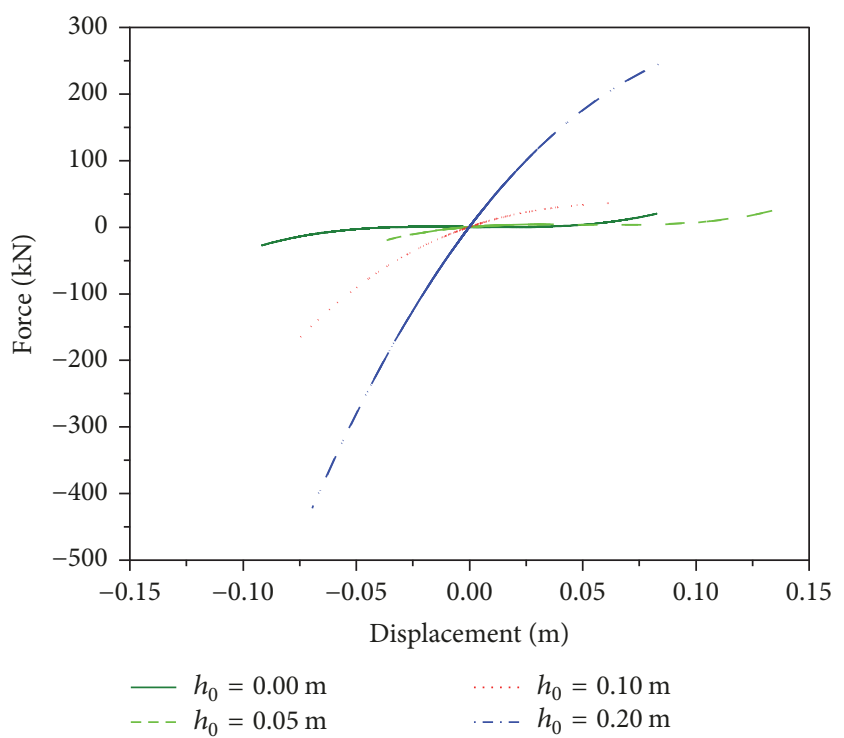

(d)

FIGURE 7: Comparison of elastic displacement versus force response curves for a seismic isolated structure with QZS: (a) Loma PrietaSaratoga-Aloha Ave.; (b) Kocaeli-Izmit; (c) Chi-Chi-TCU089; (d) Chi-Chi-CHY080.

in degrees is $\theta=30^{\circ}$. The parameter $h$ can be determined to be $0.5 \mathrm{~m}$ and $\gamma=0.87$. It is assumed that the mass reaches the position at $h_{0}=0.00 \mathrm{~m}\left(\theta=0^{\circ}\right)$ which is a QZS position. In the case of QZS position, $\beta=3.36$. At the QZS position, $\beta=3.36 . k=\beta k_{v}=6.6257 \times 10^{3} \mathrm{kN} / \mathrm{m}$. To meet the static capacity requirement, design parameters should be verified by the following formula:

$$
F_{N} \leq \widehat{F}_{d} k L
$$

Substituting the given parameters into (11) yields $\widehat{F}_{d} k L=$ $967 \mathrm{kN}$. Obviously, the result cannot meet (11). Thus, design parameters need be adjusted to meet the static capacity requirement. Here, $T$ changes from $2 \mathrm{~s}$ to $1 \mathrm{~s}$, and $L$ increases from $1 \mathrm{~m}$ to $1.2 \mathrm{~m}$. Then, $\widehat{F}_{d} k L=2321 \mathrm{kN}>F_{N}$. In this case, seismic responses of the QZS system can be obtained by numerical analysis.

In order to compare the performance between the QZS system and the seismic isolated system without QZS, we consider isolating the same mass under the same external excitation conditions. Here, rubber bearings are used for the seismic isolated system without QZS. The vertical stiffness is $1683.2 \mathrm{kN} / \mathrm{mm}$ [3]. The vertical nature period of the seismic isolated system without QZS is $0.068 \mathrm{~s}$. Figure 12 shows the 


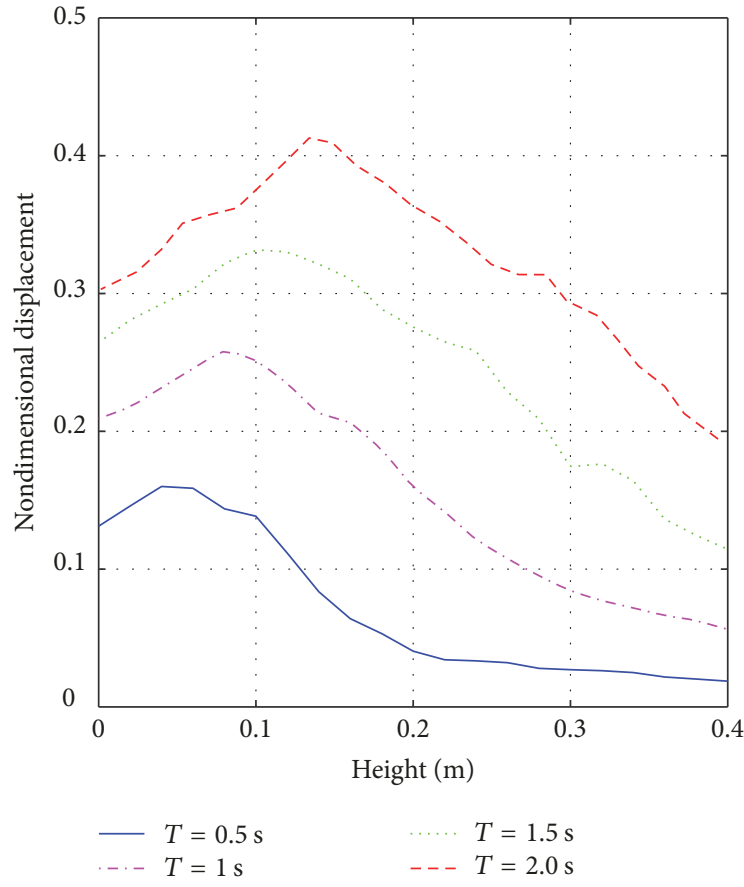

(a)

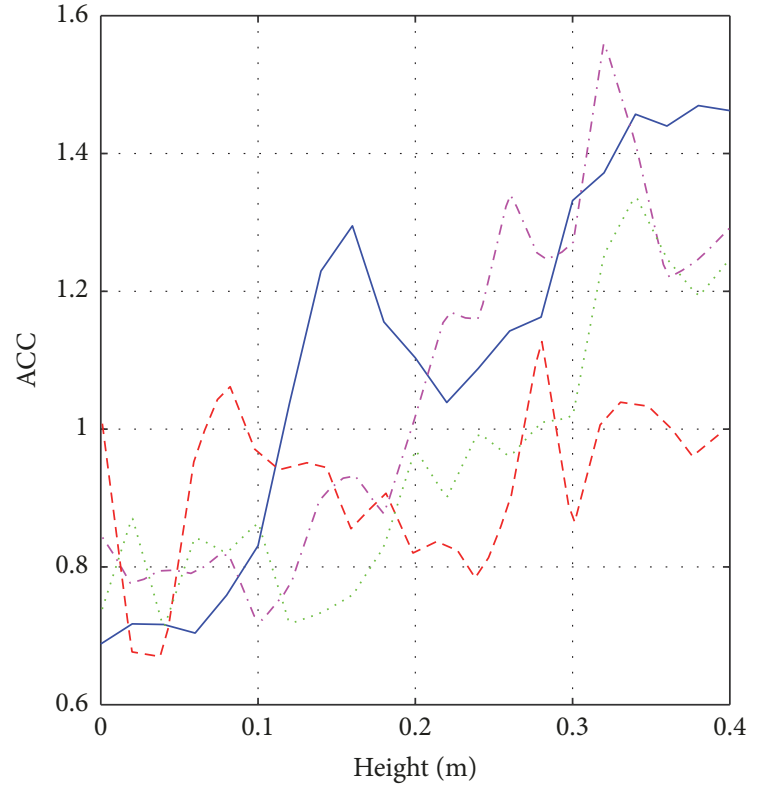

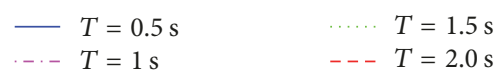

(b)

FIGURE 8: Comparison of nondimensional displacement and AAC for a seismic isolated structure with QZS $(\xi=0.05)$.

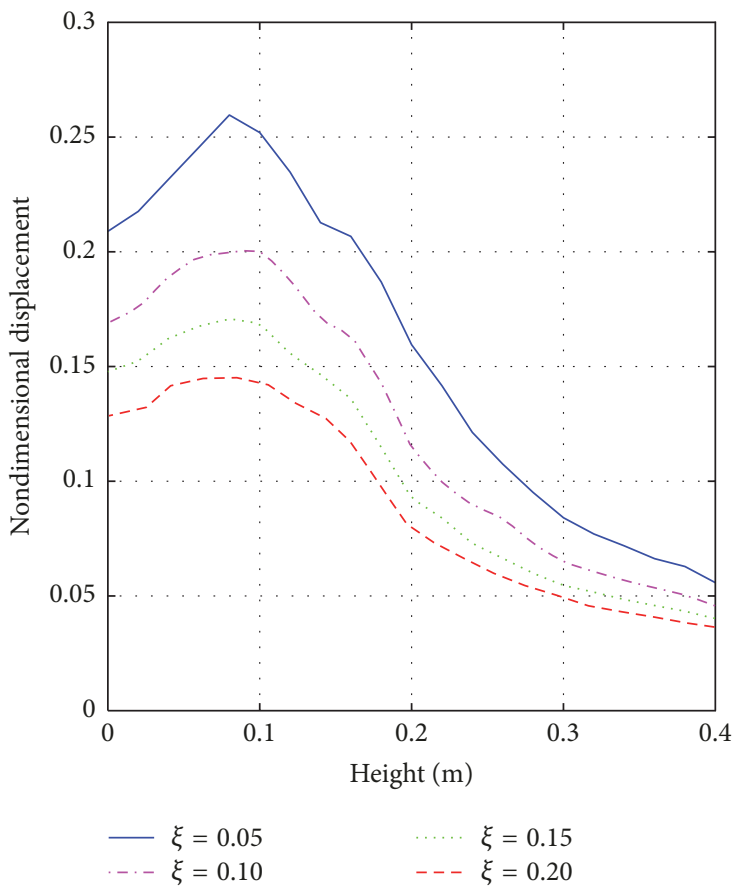

(a)

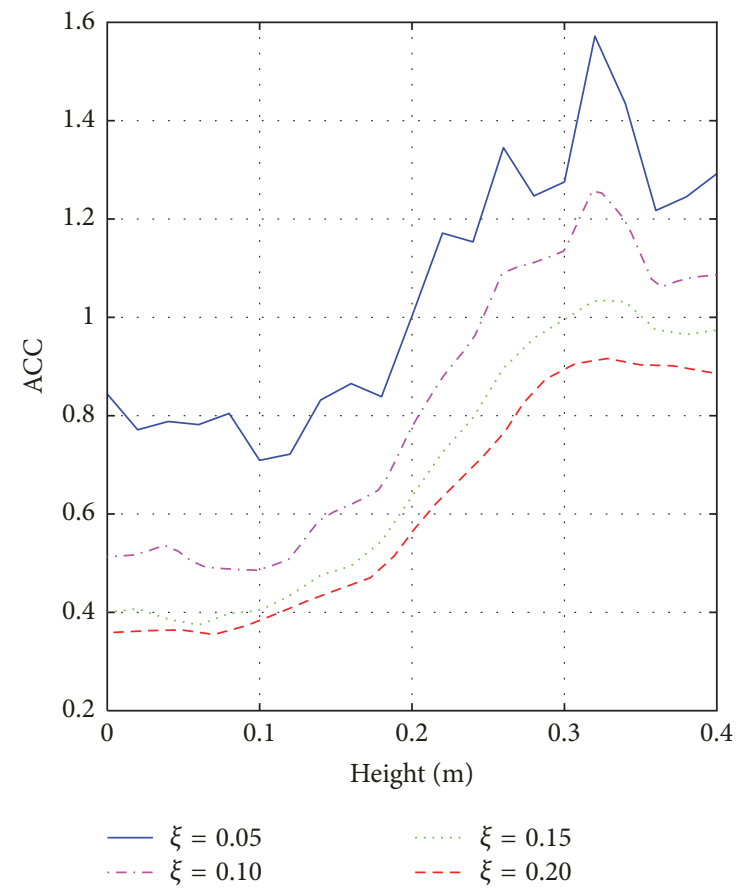

(b)

FIGURE 9: Comparison of nondimensional displacement for a seismic isolated structure with QZS $(T=1 \mathrm{~s})$. 


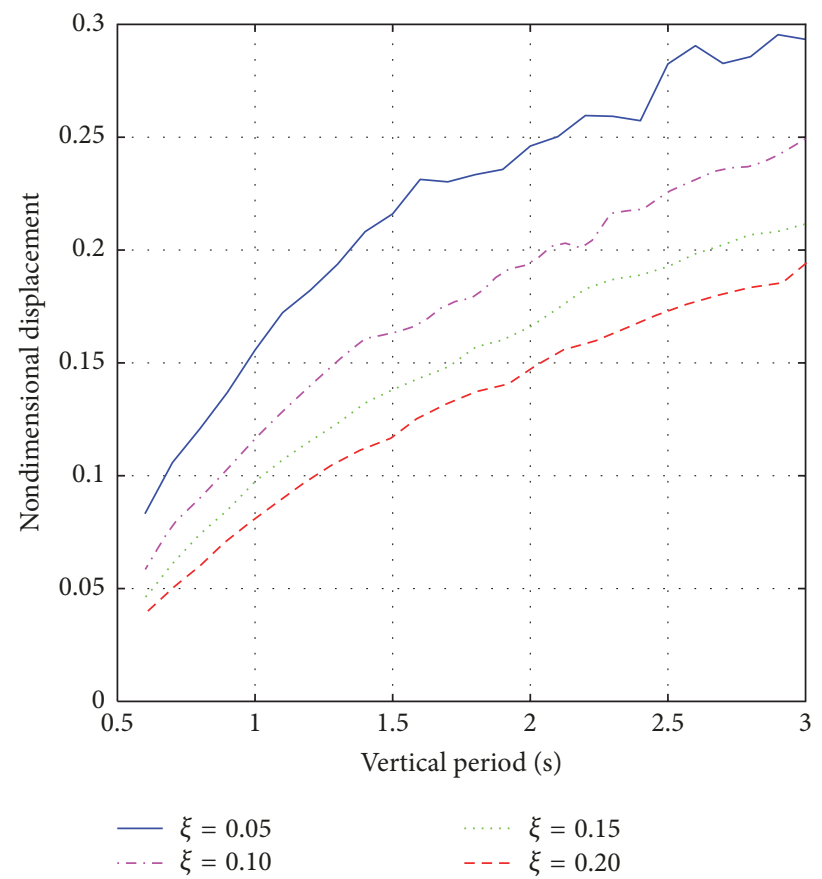

(a)

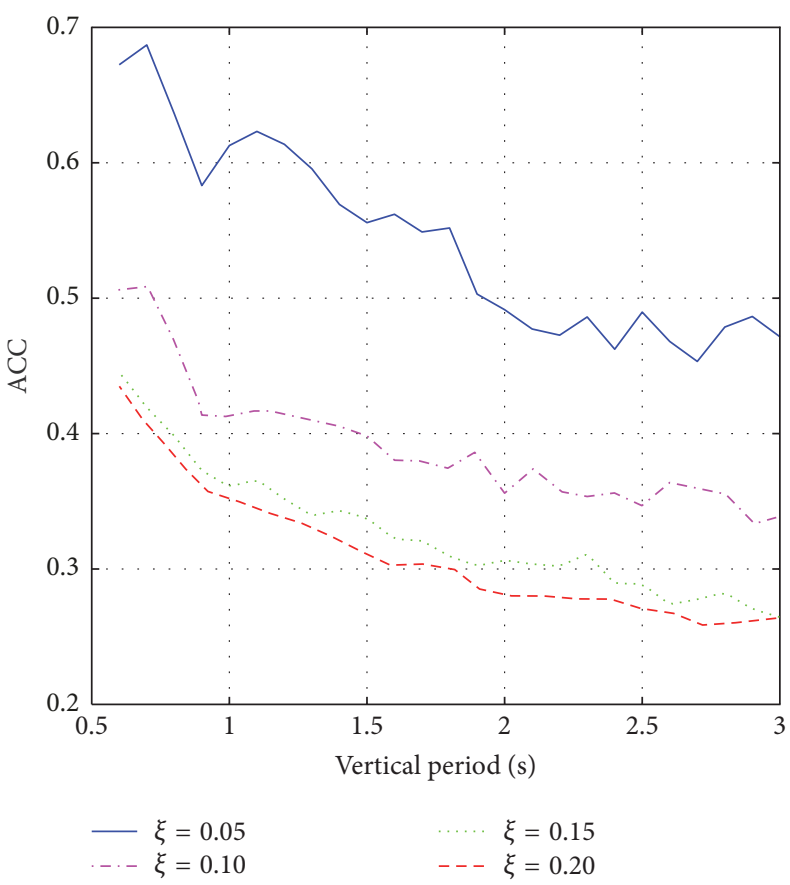

(b)

FIGURE 10: Comparison of AAC for a seismic isolated structure with QZS $\left(h_{0}=0.1 \mathrm{~m}\right)$.

results of peak absolute vertical acceleration for the QZS system and the seismic isolated system without QZS. Results from the numerical simulations show that the vertical components of ground motions cause significant amplification in the acceleration of the seismic isolated system without QZS. For example, the peak acceleration response for N2 is $11.19 \mathrm{~m} / \mathrm{s}^{2}$, and the corresponding AAC is 2.80 . The results presented in Figure 12 also suggest that the QZS concept can largely decrease the peak absolute vertical acceleration of the seismic isolated structure.

The static and seismic response analysis results show that the seismic isolation system including QZS and vertical damper is a promising strategy in NF vertical ground motions. However, the limitation of the study is that if the rated load of the system exceeds a value, it is hard to realize a good isolation efficiency. Moreover, optimization selection of the complex parameters and superior ability on deformation and load capacity for materials of this system should be taken into account for the isolation system to obtain better isolation efficiency.

\section{Conclusions}

Vertical static and nonlinear time history analyses were performed to investigate the static capacity, acceleration, and displacement responses of the seismic isolated system with QZS. From the results presented in this paper, the following conclusions are drawn:

(1) The maximum force of the vertical capacity of a seismic isolated structure with QZS is highly related to the configurative parameter, the ratio of spring stiffness, vertical stiffness, and the length of the oblique spring. For fixed vertical stiffness, the length of the oblique spring, and the ratio of spring stiffness, the maximum force of vertical capacity of a seismic isolated structure with QZS increases when the configurative parameter reduces.

(2) The effect of static equilibrium position, vertical period, and damping ratio on seismic responses for the seismic isolated system with QZS under nearfault ground motions is significant. These studies demonstrate that the seismic isolated system with QZS can provide reasonable isolation effects to control near-fault earthquakes by designing key model parameters.

(3) Although the investigation suggests that the QZS concept might be a promising strategy to achieve vertical seismic protection of base-isolated buildings, further detailed analysis and bearings product are needed when the rated load of the system exceeds a value.

(4) It is noted that the analysis results presented in this paper do not consider the effects of horizontal, rocking, and rotational ground motions. These effects are likely important and studies are needed to better quantify them and develop additional methods for their consideration in analysis and design. 


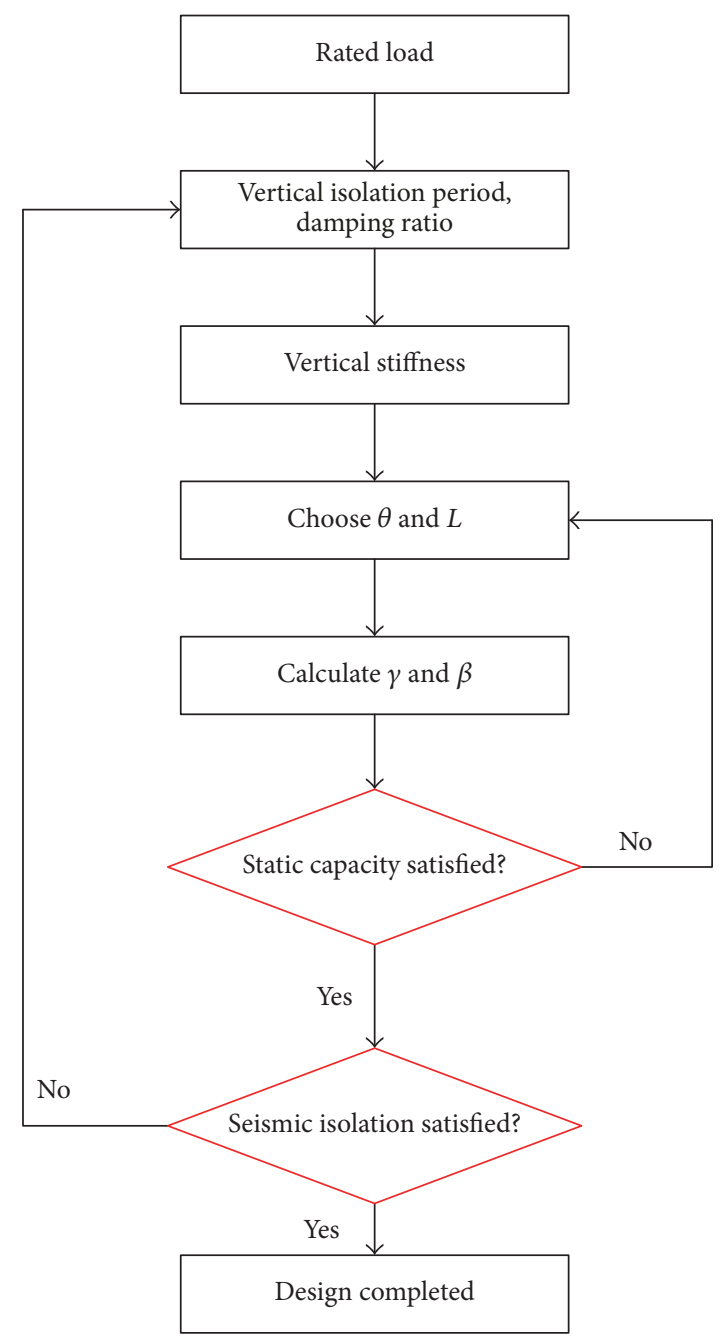

FIGURE 11: The design procedures.

(5) The analysis model in this paper is assumed to be symmetrical, without considering the eccentricity effect. It is possible to change the critical load capacity and isolation efficiency of the analysis model under vertical and horizontal ground motions simultaneously. Particularly, if the supported structure has an excessive vertical eccentricity for mass and vertical stiffness, there will be a need to control rocking responses. In addition, overturning effects can be considered when a base-isolated structure has a large length-to-width ratio.

(6) The feasibility of the seismic isolation system presented in this paper would need to be further explored including specific details of the vertical spring, damper, and oblique springs. Due to the effects of horizontal, rocking, and rotational ground motions, methods to restrain lateral deformation and rocking angle can be further studied.

\section{Notations}

m: $\quad$ Mass of a lumped parameter model for a seismic isolated structure

$L: \quad$ The length of the oblique spring

$a$ : Horizontal projection length of the oblique spring

$k_{v}, c_{v}: \quad$ The vertical spring stiffness and damping coefficient

$u$ : $\quad$ Vertical displacement of a seismic isolated structure

$f: \quad$ Vertical force applied to the mass of a seismic isolated structure

$k: \quad$ The oblique spring stiffness

$\theta: \quad$ The angle of the oblique spring to the horizon in degrees

$x$ : $\quad$ The axial deflection of the oblique spring

$\beta=k / k_{v}$ : The ratio of spring stiffness

$\gamma=a / L$ : The configurative parameter of the system

$\ddot{y}_{g}: \quad$ Vertical seismic acceleration. 


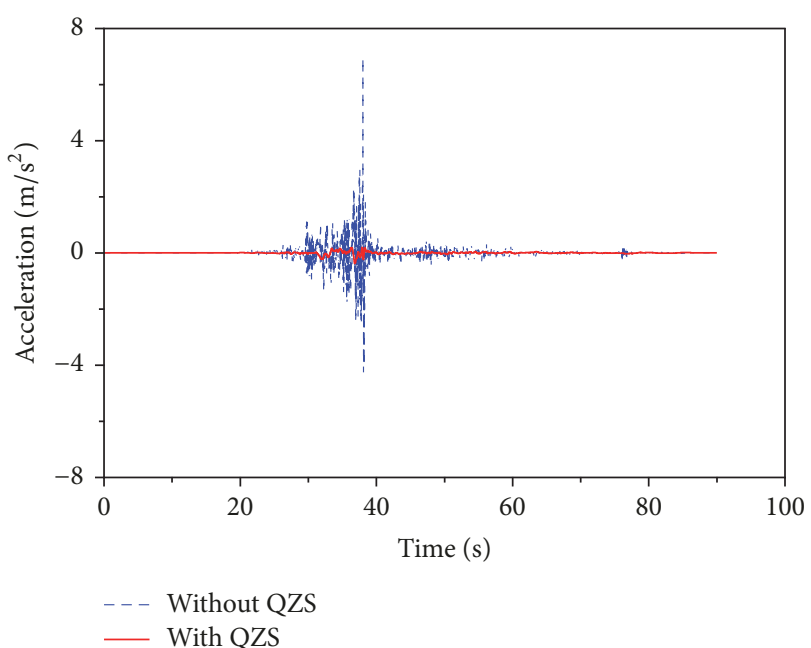

(a)

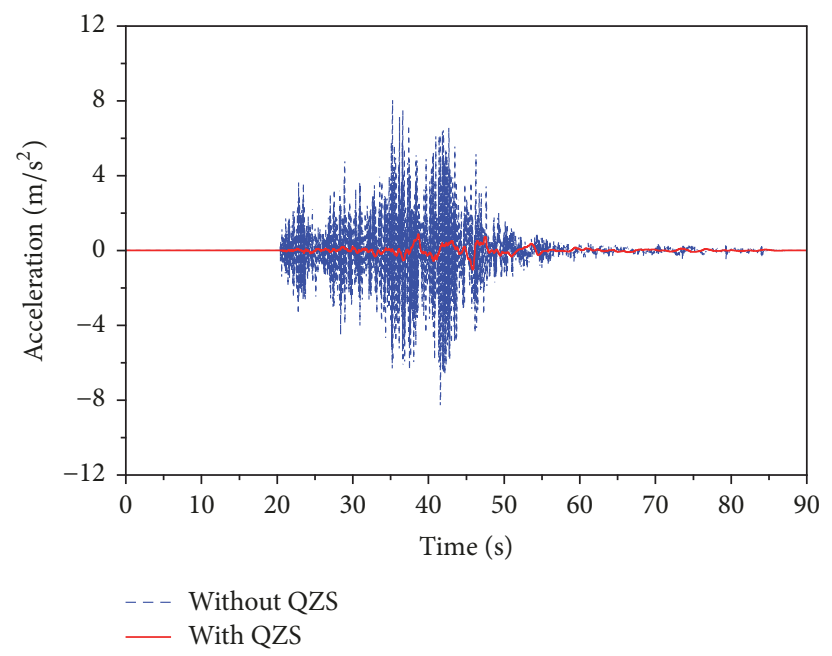

(c)

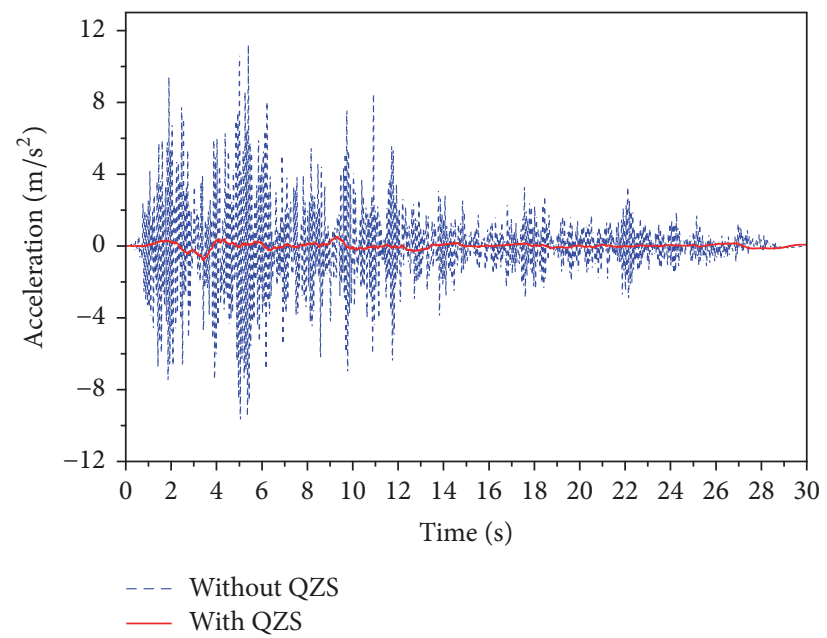

(b)

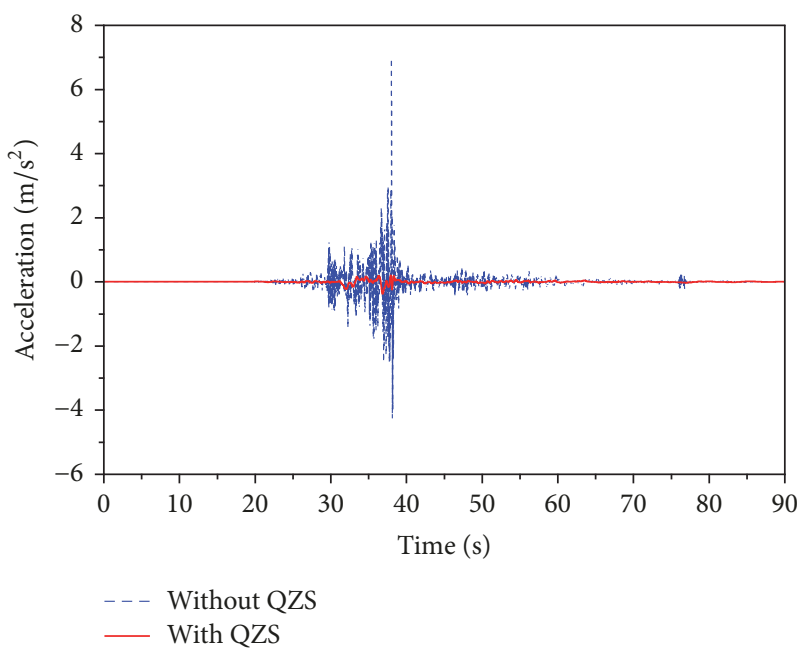

(d)

FIgure 12: Comparison of ACCs for the QZS system and the seismic isolated system without QZS: (a) Loma Prieta-Saratoga-Aloha Ave.; (b) Kocaeli-Izmit; (c) Chi-Chi-TCU089; (d) Chi-Chi-CHY080.

\section{Conflicts of Interest}

The authors declare that there are no conflicts of interest regarding the publication of this paper.

\section{Acknowledgments}

The authors gratefully acknowledge the financial support of the National Natural Science Foundation of China (no. 51508414), Yunnan Science Technology Department Fund Project (2016RA079), and Yunnan Provincial Department of Education Fund Project (2015Y298).

\section{References}

[1] S. Nagarajaiah and S. Xiaohong, "Response of base-isolated USC hospital building in Northridge earthquake," Journal of Structural Engineering, vol. 126, no. 10, pp. 1177-1186, 2000.
[2] W.-G. Liu, C. Qin, Y. Liu, and Q.-R. Yang, "Shaking table tests on earthquake response characterization of a complex museum isolated structure in high intensity area," Shock and Vibration, vol. 2016, Article ID 7974090, 23 pages, 2016.

[3] S. Furukawa, E. Sato, Y. Shi, T. Becker, and M. Nakashima, "Fullscale shaking table test of a base-isolated medical facility subjected to vertical motions," Earthquake Engineering \& Structural Dynamics, vol. 42, no. 13, pp. 1931-1949, 2013.

[4] Y. Bozorgnia and K. W. Campbell, “The vertical-to-horizontal response spectral ratio and tentative procedures for developing simplified V/H and vertical design spectra," Journal of Earthquake Engineering, vol. 8, no. 2, pp. 175-207, 2004.

[5] G. P. Warn and B. Vu, "Exploring the low shape factor concept to achieve threedimensional seismic isolation," in Proceedings of the 20th Analysis and Computation Specialty Conference, pp. 1-11, Chicago, Ill, USA, 2012.

[6] M. Morishita, K. Inoue, and T. Fujita, "Development of threedimensional seismic isolation systems for fast reactor application," Journal of Japan Association for Earthquake Engineering, vol. 4, no. 3, pp. 305-310, 2004. 
[7] T. Tomizawa, O. Takahashi, H. Aida et al., "Vibration test in a Building named "Chisuikan" using Three-dimensional Seismic Isolation System," in proceedings of the The 15th World Conference on Earthquake Engineering, 2012.

[8] B. Vu, M. Unal, G. P. Warn, and A. M. Memari, "A distributed flexibility and damping strategy to control vertical accelerations in base-isolated buildings," Structural Control and Health Monitoring, vol. 21, no. 4, pp. 503-521, 2013.

[9] T. D. Le and K. K. Ahn, "Experimental investigation of a vibration isolation system using negative stiffness structure," International Journal of Mechanical Sciences, vol. 70, pp. 99-112, 2013.

[10] Y. Zheng, X. Zhang, Y. Luo, B. Yan, and C. Ma, "Design and experiment of a high-static-low-dynamic stiffness isolator using a negative stiffness magnetic spring," Journal of Sound and Vibration, vol. 360, pp. 31-52, 2016.

[11] M. Dicleli and S. Buddaram, "Equivalent linear analysis of seismic-isolated bridges subjected to near-fault ground motions with forward rupture directivity effect," Engineering Structures, vol. 29, no. 1, pp. 21-32, 2007.

[12] R. S. Jangid and J. M. Kelly, "Base isolation for near-fault motions," Earthquake Engineering \& Structural Dynamics, vol. 30, no. 5, pp. 691-707, 2001.

[13] L. Y. Lu, P. R. Chen, and K. W. Pong, "Theory and experiment of an inertia-type vertical isolation system for seismic protection of equipment," Journal of Sound and Vibration, vol. 366, pp. 4461, 2016.

[14] S. K. Kunnath, E. Erduran, Y. H. Chai, and M. Yashinsky, "Effect of near-fault vertical ground motions on seismic response of highway overcrossings," Journal of Bridge Engineering, vol. 13, no. 3, pp. 282-290, 2008.

[15] A. Carrella, M. J. Brennan, and T. P. Waters, "Static analysis of a passive vibration isolator with quasi-zero-stiffness characteristic," Journal of Sound and Vibration, vol. 301, no. 3-5, pp. 678689, 2007.

[16] C. C. Lan, S. A. Yang, and Y. S. Wu, "Design and experiment of a compact quasi-zero-stiffness isolator capable of a wide range of loads," Journal of Sound and Vibration, vol. 333, no. 20, pp. 4843-4858, 2014.

[17] B. Chiou, R. Darragh, N. Gregor, and W. Silva, "NGA project strong-motion database," Earthquake Spectra, vol. 24, no. 1, pp. 23-44, 2008.

[18] E. I. Katsanos, A. G. Sextos, and G. D. Manolis, "Selection of earthquake ground motion records: a state-of-the-art review from a structural engineering perspective," Soil Dynamics and Earthquake Engineering, vol. 30, no. 4, pp. 157-169, 2010. 


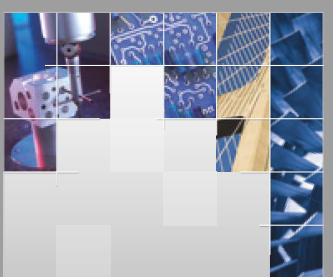

\section{Enfincering}
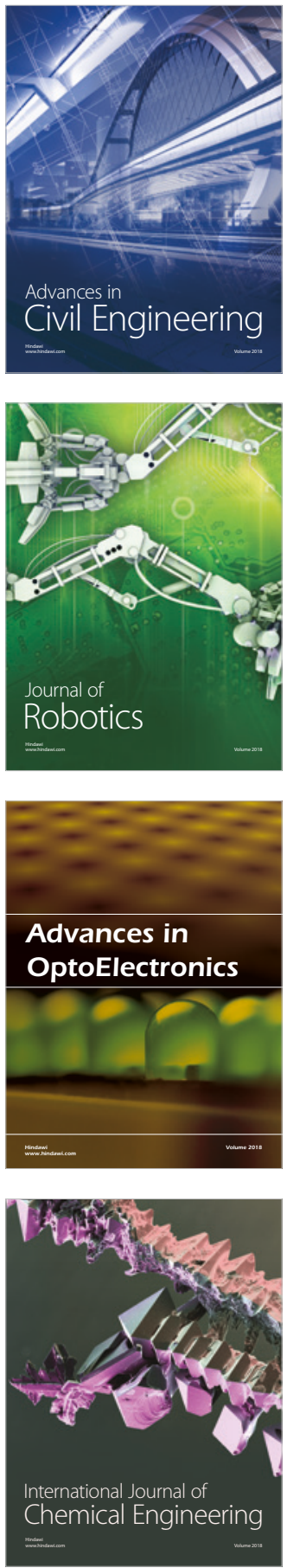

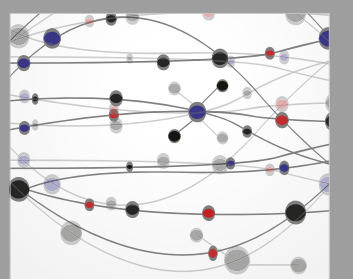

\section{Rotating \\ Machinery}

The Scientific World Journal

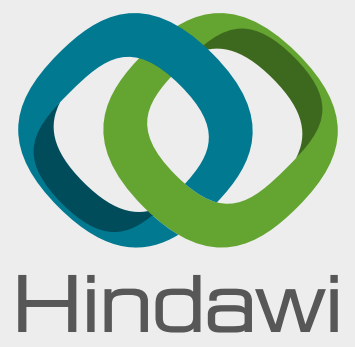

Submit your manuscripts at

www.hindawi.com
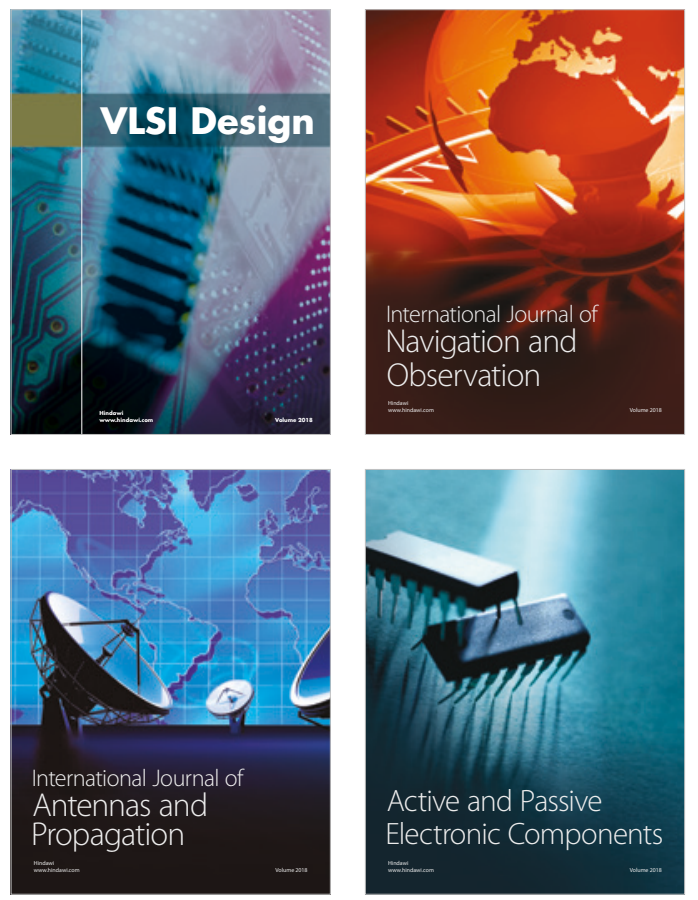
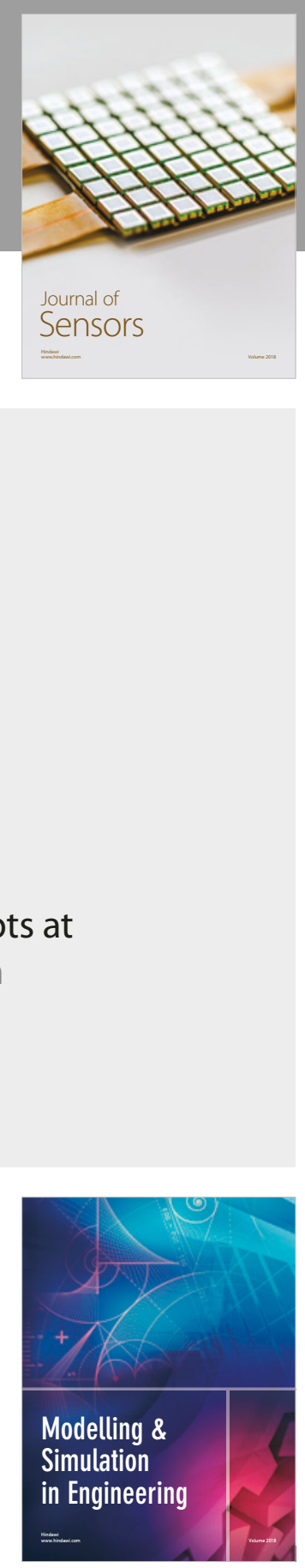

\section{Advances \\ Multimedia}
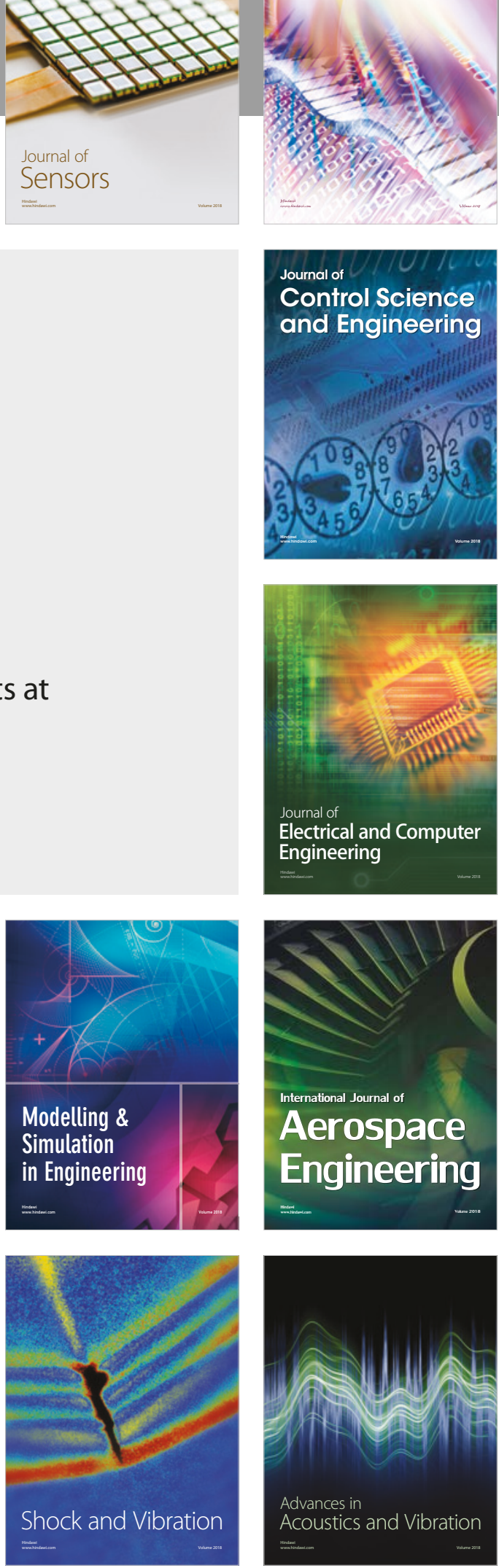